\title{
LIFECYCLE ENERGY CONSUMPTION PREDICTION OF RESIDENTIAL BUILDINGS BY INCORPORATING LONGITUDINAL UNCERTAINTIES
}

\author{
Endong WANG, Zhigang SHEN \\ Durham School of Architectural Engineering and Construction, \\ University of Nebraska-Lincoln, NE 68588-0500, USA
}

Received 19 Sep 2012; accepted 24 Oct 2012

\begin{abstract}
Accurate prediction of buildings' lifecycle energy consumption is a critical part in lifecycle assessment of residential buildings. Longitudinal variations in building conditions, weather conditions and building's service life can cause significant deviation of the prediction from the real lifecycle energy consumption. The objective is to improve the accuracy of lifecycle energy consumption prediction by properly modelling the longitudinal variations in residential energy consumption model using Markov chain based stochastic approach. A stochastic Markov model considering longitudinal uncertainties in building condition, degree days, and service life is developed: 1) Building's service life is estimated through Markov deterioration curve derived from actual building condition data; 2) Neural Network is used to project periodic energy consumption distribution for each joint energy state of building condition and temperature state; 3) Lifecycle energy consumption is aggregated based on Markov process and the state probability. A case study on predicting lifecycle energy consumption of a residential building is presented using the proposed model and the result is compared to that of a traditional deterministic model and three years' measured annual energy consumptions. It shows that the former model generates much narrower distribution than the latter model when compared to the measured data, which indicates improved result.
\end{abstract}

Keywords: lifecycle energy consumption, prediction, Markov chain, neural network.

Reference to this paper should be made as follows: Wang, E.; Shen, Z. 2013. Lifecycle energy consumption prediction of residential buildings by incorporating longitudinal uncertainties, Journal of Civil Engineering and Management 19(Supplement 1): S161-S171. http://dx.doi.org/10.3846/13923730.2013.802744

\section{Introduction}

A major challenge in estimating building's lifecycle energy consumption is how to adequately address the longitudinal variations of the parameters in the lifecycle energy consumption model. The longitudinal variation can be caused by the physical condition deterioration of the buildings (inner factor) and/or by the different weather conditions over the building's service life time.

In deterministic lifecycle energy consumption model, for each type of building, its lifecycle energy consumption can be simply expressed as (Fay et al. 2000; Junnila, Horvath 2003):

$$
\mathrm{LEC}=\mathrm{AEC} \times \mathrm{BSL},
$$

where: LEC represents lifecycle energy consumption; AEC represents annual energy Consumption; and BLS represents buildings' service life.

Building's annual energy consumption is often derived from a simple average of historical data (for existing buildings) or from simulations (for new buildings) with predefined parameters and boundary conditions. Building's service life, on the other hand, is often predetermined using fixed values such as 50, 75 or 100 years (Fay et al. 2000; Khasreen et al. 2009).
In reality, different buildings' annual energy consumptions vary considerably due to temporal and spatial variability of buildings and due to the differences in residential envelope thermal property, orientation, climate condition, occupants' behaviour and others (de Wilde et al. 2011; Guerra-Santin, Itard 2010; Tsikaloudaki et al. 2012; Wang et al. 2011a; Cole, Kernan 1996; Kaynakli 2011; Biekša et al. 2011).

The same is true of building's service life. Buildings' service lives vary from building to building and the corresponding range could be very large, due to the diversity in their design level, material use, workmanship quality, external climate, operational environment and maintenance level (Mc Duling 2006). For instance, according to the survey of the year 2009, the U.S. residential service lifetime is averaged to be 61 years but presents a wide $90 \%$ confidence range of 21 to 105 years. And building's service life's probabilistic distribution changes over time (Fig. 1) (Aktas, Bilec 2012).

Considering the existence of these variations developing a stochastic model that incorporates the identified uncertainties in both annual energy consumptions and building's service life is necessary (Trombe et al. 2012; de Wilde, Tian 2011) to improve the prediction of buildings' lifecycle energy consumptions. 


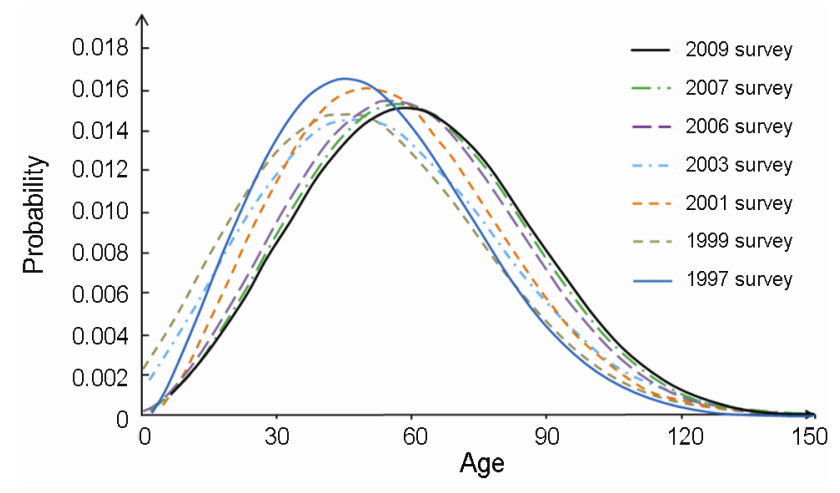

Fig. 1. The U.S. residential service life distributions (Modified on Aktas, Bilec 2012)

Models and approaches predicting periodical building energy use (e.g. hourly, daily, monthly or yearly) considering the differences of energy consumption influencers (e.g. building external envelope U-value, ambient climate, building area, and so forth) were proposed. They included regression analysis (Catalina et al. 2008), Fourier series models (Dhar et al. 1998), decision tree (Tso, Yau 2007), support vector machine and neural network (Zhao, Magoulès 2012).

Among of them, the neural network based artificial intelligence technique appears to be more accurate (Zhao, Magoulès 2012) due to its capability in adapting itself to the unforeseen pattern changes in the new available data (Catalina et al. 2008; Yalcintas, Akkurt 2005). Yalcintas and Akkurt (2005) applied neural network to predict the chiller energy consumption in a tropical climate using both climatic and chiller data. Two adaptive neural networks were proposed and tested by Yang et al. (2005) using simulated and measured data for building energy consumption prediction. Tso and Yau (2007) compared regression analysis, decision tree and neural network for the prediction of household electricity energy consumption in Hong Kong based on the electricity consumption survey data and obtained comparable results.

However, the existing models using neural network approach have significant limitations when applied to building's lifecycle energy consumption due to the lack of models to address the longitudinal variations of the input parameters (e.g. future residential condition, future ambient climate status, etc.), which are stochastic in nature (Mc Duling 2006; Hussain, Ansari 2010; Wang et al. 2011 b; de Wilde et al. 2011).

For a specific building candidate, the short term occupants' behaviour (e.g. hourly) varies but can be predicted based on historical data (Wang et al. 2011b), nevertheless, the long term behaviour (e.g. yearly or for even longer period) is relatively steady (i.e. repeats from year to year) for the fixed occupants. But it is difficult to predict (de Wilde et al. 2011). As a result, in most cases, the longitudinal variation in buildings' annual energy consumption could be explained by building envelope thermal property and climate variation (Day, Karayiannis 1999; de Wilde et al. 2011; Zhao, Magoulès 2011; Kim, Moon 2009).
Markov Chain, as a stochastic modelling tool, is capable of providing the statistical properties of future state at a given point based on the current state of a random process with Markov property using the historical data by a series of mathematical operations (Ross 1996). Markov Chain technique has been extensively used for modelling longitudinal variability, e.g. the wind power fluctuations (Trombe et al. 2012), as well as the deterioration of infrastructures (Kamaitis 2009), building components (like roof) and the whole building (Camahan et al. 1987; Madanat et al. 1995; Riveros, Arredondo 2010; Mc Duling 2006; Coffelt et al. 2010; Jiang et al. 1988), through which their practical service lifetimes can be predicted. Air temperature changes can also be modelled by Markov Chain technique (Yang et al. 2011; Hussain, Ansari 2010; Jordan, Talkner 2000; Nicolis 1990; Stamp 2012).

Based on the existing models predicting periodical building energy use, and research on Markov Chain models handling stochastic phenomenon, a Markov Chain based model for projecting lifecycle energy consumption is proposed in the paper to address the longitudinal uncertainties in annual energy consumption, building's service life and the corresponding linear-average algorithm.

Four subtasks are included: 1) A building Markov deterioration model is established based on building condition assessment through which the practical building service lifetime is estimated; 2) The ambient temperature variation is simulated using Markov Chain by examining the transition of the degree day level; 3) The annual energy consumption distribution for each possible combination of building condition and degree-day level is projected through neural network technique based on a measured dataset; 4) The transition between the possible energy consumption state (i.e. joint states of building condition and degree day level) is determined by the transition probability matrices (TPMs) in the established building Markov deterioration model and the temperature transition model. The lifecycle energy consumption is then aggregated with probabilistic approach, which is an improvement over the simple liner-average algorithm in the deterministic models. A residential building case is presented using the proposed stochastic approach and the traditional deterministic approach. The probabilistic lifecycle energy consumption is calculated and is compared to the value of the deterministic approach.

\section{Methodology}

\subsection{Markov Chain model}

\subsubsection{Markov Chain basics}

Markov Chain model can be used for simulating the random process with Markov properties (Ross 1996): 1) Future states are unknown; 2) The next state depends only on the current state and is independent of the sequence of past events; 3) The transition probability between the states is constant over time. For a typical discrete-time stochastic process $\left\{X_{(t)}, t=0,1,2, \ldots\right\}$ with the discrete state space of $\left\{j_{0}, j_{1}, j_{2}, \ldots\right\}$, the Markov Chain model can be mathematically described by: 


$$
\begin{aligned}
p\left(X_{t+1}=\right. & \left.j_{t+1} \mid X_{t}=j_{t}, X_{t-1}=j_{t-1}, \ldots, X_{1}=j_{1}, X_{0}=j_{0}\right)= \\
& p\left(X_{t+1}=j_{t+1} \mid X_{t}=j_{t}\right),
\end{aligned}
$$

where: $j_{1}, j_{2}, \ldots, j_{t}, j_{t+1}$ are a finite number of possible states for $X t ; p$ is the conditional probability function.

Given the initial state vector is $r$, and $P$ is the transition probability matrix (TPM), after $n$ time steps in the stipulated period of $\tau$, the condition vector $p_{n}$ will be:

$$
p_{n}=r P^{(n)}=r P^{n}=r P^{\tau / T},
$$

where: $p_{n}$ is state vector with $m$ elements at time step $n$; $T$ is the time interval of the observations.

The corresponding expected state is:

$$
E\left(I_{n}\right)=\sum_{i=1}^{m} i * p_{n}(i)
$$

where: $E\left(I_{n}\right)$ is the expected state; $i$ is the state value; $p_{n}(i)$ is the probability for the system to take the value $i$.

\subsubsection{Methods for deriving Transition Probability Matrices (TPMs)}

The development of TPM is one essential component in using Markov Chain based models. Namely, the difficulty in determining transition probabilities has been recognized to be one of major barriers for the wide application of Markov chain based models (Ortiz-Garcia et al. 2006).

1) The conceptual approach - counting method

The conceptual way for deriving TPM is the counting method (Jiang et al. 1988; Ortiz-Garcia et al. 2006). The prerequisite for using counting method is the collection of the sufficient standard data that are the time-series data from the history of the same (or similar) target stochastic process during a relatively long observing period. The typical element of a TPM P can be calculated by the follows:

$$
p_{a, b}=n_{a, b} / n_{a}
$$

where: $n_{a, b}$ is the counts of transitions from the state $a$ to the state $b ; n_{a}$ is the total counts of transitions going out from the state $a$.

\section{2) The expected-value method}

In most cases, sufficient standard data are not readily available which makes it infeasible to apply the counting method in deriving TPM. Several further methods have been developed for dealing with this type of data scarcity situations, like fuzzy logic artificial intelligence (Mc Duling 2006), ordered probit technique based method (Madanat et al. 1995), expected-value (or so called "linear regression") method (Carnahan et al. 1987), expert judgment (Zhang et al. 2005), hybrid approach combining random sampling and regression (Riveros, Arredondo 2010) and so forth. All these methods have their own virtues and shortcomings. Among them, the one easiest and frequently used has been the expected-value method (Carnahan et al. 1987; Riveros, Arredondo 2010; Agrawal et al. 2009; Jiang et al. 1988; Madanat et al. 1995; Ortiz-Garcia et al. 2006).

The detailed procedure of expected-value method for deriving TPM can be processed as follows (Carnahan et al. 1987; Ortiz-Garcia et al. 2006; Madanat et al. 1995):

Step 1: Choosing the residential buildings similar to the targeted one from data pool. This takes into account the fact that residential deterioration rate is a function of several previously stated explanatory variables (factors). These selected samples of distinct vintage present a series of residential condition ratings and age data.

Step 2: Using the (residential condition ratings) RCR as the dependent variable and the age as the independent variables to develop the following linear regression model:

$$
R C R=\alpha+\beta^{*} A g e+\varepsilon,
$$

where: $\alpha$ and $\beta$ are the parameters to be determined; $\varepsilon$ is random term for residuals.

Step 3: Using nonlinear optimization algorithm to estimate TPM by minimizing the distance measure between the estimated condition ratings from Eqn (6) and the expected condition ratings derived from the desired Markov chain model according to Eqn (4). The mathematical expression of the optimization process is shown in:

$$
\begin{gathered}
Z=\min \sum_{\text {Age }}\left(R \hat{C} R_{\text {Age }}-E\left(I_{n}\right)_{\text {Age }}\right)^{2} \\
\text { Subject to } \\
0 \leq p_{a b} \leq 1 ; \quad a, b=1,2, \ldots, m \\
\sum_{b=1}^{m} p_{a b}=1 ; \quad a=1,2, \ldots, m
\end{gathered}
$$

where: $R \hat{C} R_{A g e}$ and $E\left(I_{n}\right)_{\text {Age }}$ are the estimated RCR and the expected RCR at some age point derived from Eqns (6) and (4), respectively; $m$ is the size of TPM.

\subsection{Neural network model}

Neural network models have been extensively utilized for nonlinear prediction in many cases through mimicking the neurophysiology properties of the biological neurons of the human brain (Yu et al. 2011). Specifically, it generally predicts the new events via the critical learning and training process on other existing events, especially useful in the situation of unknown relationship between the inputs and outputs (Tso, Yau 2007). A typical information processing unit in neural network is shown in Figure 2.

The feed-forward network in which the information flow only moves forward (from the input layer, through the hidden layer, finally to the output layer) is the most commonly used network type (Tso, Yau 2007). Its output error gradient is often calculated by back-propagation algorithm for learning and training process in which the weights of the inputs (Fig. 2) are updated and determined. 


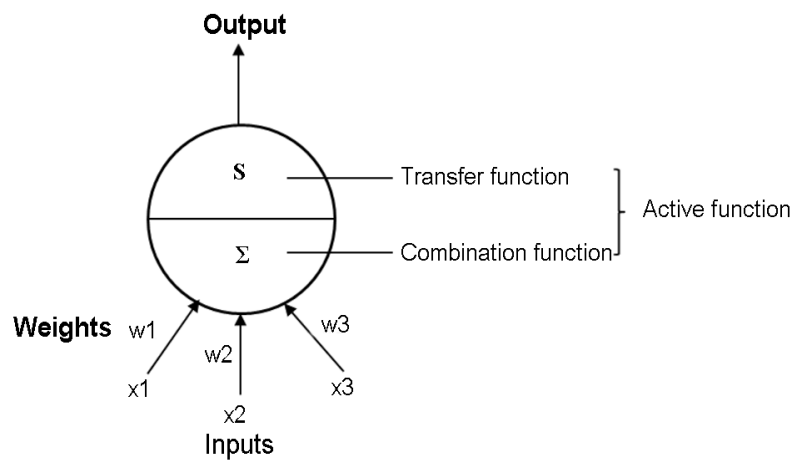

Fig. 2. Typical processing unit in neural network (Tso, Yau 2007)

The improved resilient back-propagation (iRPROP) training algorithm is one of the best and fastest neural network training methods and it often performs well in most cases based on its good ability of adaption (Igel, Husken 2000). The multilayer perception with iRPROP training is used for predicting the Energy Use Intensity (EUI) of the residential. The activation function for both hidden and output layers is sigmoid:

$$
\operatorname{Sigmoid}(x)=1 /(1+\exp (-x)) \text {. }
$$

The total number of the layers is often set to three (one input layer, one hidden layer and one output layer) (Yu et al. 2011).

\subsection{Fuzzy C-Means Clustering}

The state space for a typical Markov Chain is discrete and finite. Annual degree-day information (including heating degree-day and cooling degree-day) is usually continuous. To use Markov Chain for modelling degree-day level transition process, the clustering technique which is a mathematical algorithm for identifying the "nature" classes (clusters) of objects from data sets, is used for levelling the heating degree-day and cooling-degree-day information. Particularly, Fuzzy C-Means is adopted to avoid the rigid clustering problem (Dunn 1973) by minimizing the following objective function with the iterative algorithm until the desired criterion is satisfied:

$$
\begin{gathered}
\sum_{i=1}^{C} \sum_{j=1}^{K} \mu_{j i}{ }^{v}\left\|A_{j}-C_{i}\right\|^{2} \\
\mu_{j i}=1 / \sum_{m=1}^{C}\left(\left\|A_{j}-C_{i}\right\| /\left\|A_{j}-C_{m}\right\|\right)^{2 /(v-1)} \\
C_{i}=\left(\sum_{j=1}^{K} \mu_{j i}^{v} A_{j}\right) /\left(\sum_{j=1}^{K} \mu_{j i}^{v}\right)
\end{gathered}
$$

where: $C$ is the number of cluster centres; $K$ is the number of measured data points; $v$ is weighting index $(>1)$; $A_{j}$ is the $j^{\text {th }}$ measured data; $C_{i}$ is the centre of the cluster $\mathrm{I} ; \mathrm{u}_{\mathrm{ji}}$ is the degree of membership of $A_{j}$ in the cluster $I$; and $\left\|^{*}\right\|$ is expressing the similarity between measured data and the centroid.

\subsection{Stochastic lifecycle energy consumption model development}

The proposed stochastic model consists of three submodels (Fig. 3). The first sub-model is the building Markov deterioration model, through which, the building service life and the expected building condition at the specific time point can be computed. The second submodel is the degree-day Markov transition model, via which the expected DD level around the building's location at the specific time point can be forecasted. The third sub-model is the annual energy consumption Markov transition model used to calculate the expected energy consumption level and the lifecycle energy consumption within the predicted service lifetime.

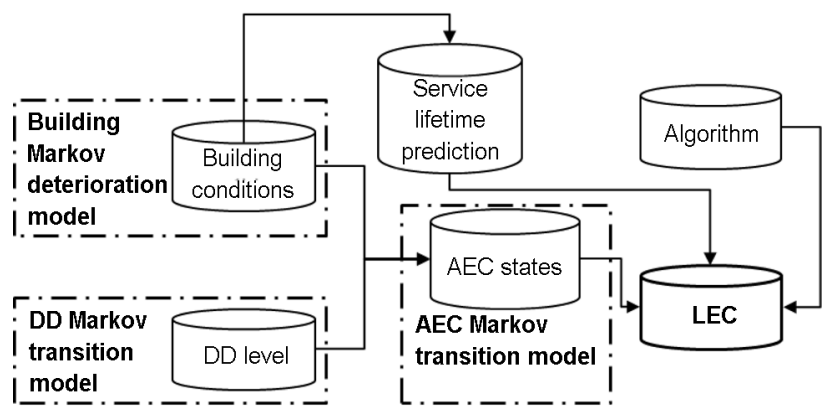

Fig. 3. The stochastic lifecycle energy consumption model (AEC represents Annual Energy Consumption; DD represents Degree-day; LEC represents Lifecycle Energy Consumption)

\subsubsection{The building Markov deterioration model}

Six-point scale building condition assessment system (Table 1) (Barry 2011) will be used for evaluating the building envelope condition and indicating the level of the thermal property. Although it is not accurate enough, it is still the mainstream approach due to its convenience (Straub 2009). Then the state space, which contains a set of possible building condition states, is defined as $S=\{6$, $5,4,3,2,1\}$. For a specific building, the state value at some time point can be observed based on the predefined rating criteria. It is assumed that the building degradation process is continuous from the long trend perspective

Table 1. Building condition assessment table (Modified based on Straub 2009; Mc Duling 2006; Barry 2011)

\begin{tabular}{ccl}
\hline Rating Condition & \multicolumn{1}{c}{ Brief criteria } \\
\hline 6 & Excellent & $\begin{array}{l}\text { "Like new" and only planned preventative } \\
\text { maintenance is needed } \\
\text { Degradation starts and planned and/or } \\
\text { unplanned condition-based maintenance } \\
\text { actions are needed } \\
\text { Object is still functional normally but } \\
\text { medium repairs are needed to return its } \\
\text { satisfactory condition } \\
\text { Object is still functional but major repairs } \\
\text { are needed to return its satisfactory condi- } \\
\text { tion } \\
\text { Object is still functional but in need of } \\
\text { rehabilitation to return its satisfactory } \\
\text { condition } \\
\text { Object is dysfunctional and needs to be } \\
\text { replaced }\end{array}$ \\
& Foor \\
\hline
\end{tabular}




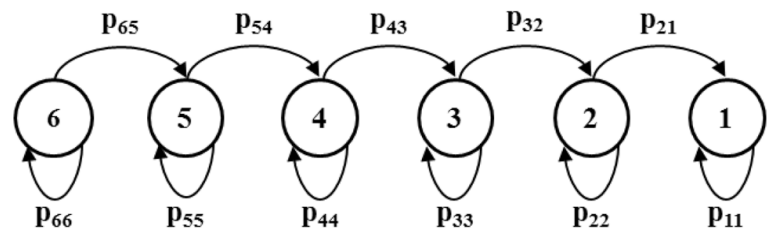

Fig. 4. Markov process for building deterioration

(Fig. 4), i.e. the building can only transit from a better state to its adjacent worse state in one time step (Coffelt et al. 2010; Mc Duling 2006). Building condition data is often supplied in the form of the same time point assessment on different building objects, which is similar to other structures, like pavement (Carnahan et al. 1987). Therefore, the transition probability matrix $P$ can be obtained by the foregoing expected-value method. In this study, Matlab code on the basis of FMINCON function is made to implement the above nonlinear optimizing process. The expected building condition at specific time point can be calculated through following Eqns (3) and (4) and the service life can be predicted by defining targeted condition to be "3" (Fig. 5).

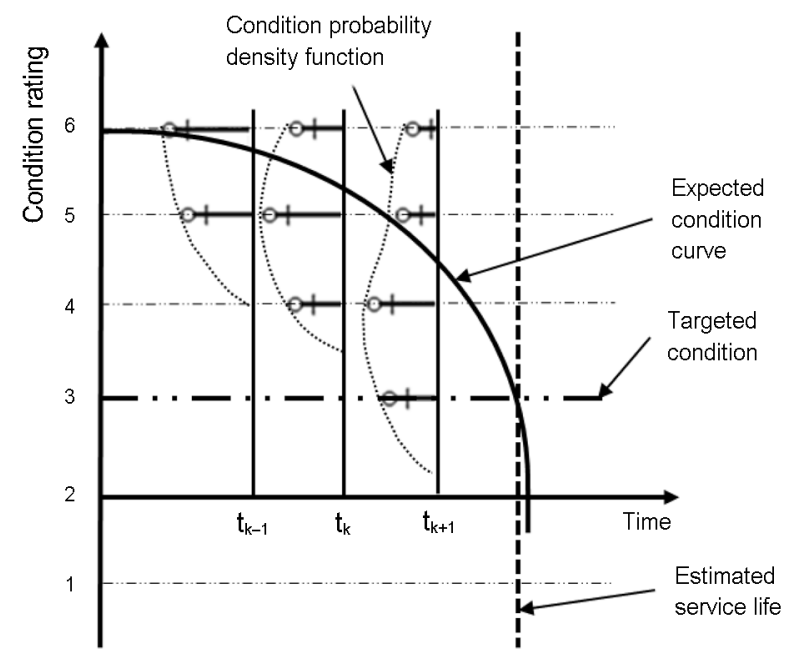

Fig. 5. Service life prediction (based on Hovde, Moser 2004)

\subsubsection{The degree-day Markov transition model}

Degree-days can be used to represent the ambient temperature level (Day, Karayiannis 1999). According to previous study, the longitudinal variation of degree-day can also be simulated by Markov Chain, an example can be seen in Figure 6 (Yang et al. 2011; Hussain, Ansari 2010; Jordan, Talkner 2000; Nicolis 1990; Stamp 2012). Before the model development, the annual degree-day needs to be classified into different classes (e.g. $C_{1}, C_{2}$, $C_{3}, \ldots$ ) by clustering technique using heating degree-day and cooling degree-day to describe two-dimensional degree-day level. The transition probability between classes

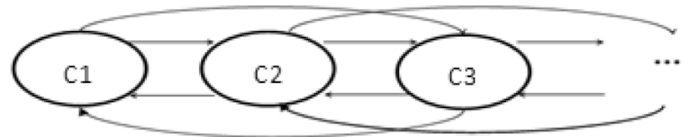

Fig. 6. Degree day transition process can be obtained by the stated counting method. The expected degree-day level at specific time can also be calculated by Eqns (3) and (4).

\subsubsection{The annual energy consumption Markov transition model}

Building conditions and degree-day states are jointed to describe the possible annual energy consumption states (Fig. 7). The transition probability between the joint states can be computed by Eqn (10) assuming the annual building condition is independent of the degree-day state:

$$
p\left(i, C_{j} \mid k, C_{l}\right)=p(i \mid k)^{*} p\left(C_{j} \mid C_{l}\right),
$$

where: $i$ and $k$ are building conditions; $C_{j}$ and $C_{l}$ are degree-day states.

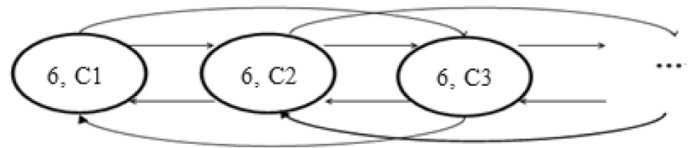

Fig. 7. Annual energy consumption transition process

Since many other factors, such as residential style, floor area and so forth, can also affect the energy consumption, for each fixed joint state, the probabilistic distribution of EUI will be generated through neural network by changing other influencing parameters. Then the lifecycle energy consumption can be calculated based on:

$$
p_{E, y}=q P_{E}^{(y)} ; E_{y}=\sum_{i, j} E_{i, C_{j}} * p_{E, y, i, C_{j}} ; E_{\text {total }}=\sum_{y} E_{y},
$$

where: $p_{E, y}$ is state vector at time step $y ; p_{E, y, i, C_{j}}$ is the probability for the system to take the state $(i, C j) ; P_{E}$ is the transition probability matrix; $q$ is the initial state vector; $E_{y}$ is the annual energy consumption at time step $y ; E_{i, C_{j}}$ is the annual energy consumption for $(i, C j) ; E_{\text {total }}$ is lifecycle energy consumption.

\subsection{Comparison and validation}

Two indicators including the "shape" parameter which is the coefficient of variance $(\mathrm{COV})$ and the "position" parameter which is distance are used for measuring the difference between the resulting distributions. $C O V$ is a normalized indicator for measuring the dispersion of probability distribution. The larger COV value indicates the higher variability. Distance is an indicator for measuring the position difference between intervals and the larger value means farther distance. $C O V$ can be calculated as:

$$
\mathrm{COV}=\text { Standard Deviation/Mean . }
$$

In particular, the distances between 10 and $90 \%$ certainty intervals of the resulting distributions are calculated. Distance can be calculated as (Xu, Sun 2002; Wang et al. 2012): 


$$
D\left(I_{p}, I_{q}\right)=\sqrt{\left(V_{q}{ }^{L}-V_{p}{ }^{L}\right)^{2}+\left(V_{q}^{U}-V_{p}^{U}\right)^{2}},
$$

where: $I_{p}$ and $I_{q}$ are intervals with the lower bounds $V_{p}^{L}$, $V_{q}^{L}$ and the upper bounds $V_{p}{ }^{U}$ and $V_{q}^{U}$, respectively. In other words, $I_{p}=\left[V_{p}^{L}, V_{p}^{U}\right], I_{q}=\left[V_{q}^{L}, V_{q}^{U}\right]$.

\section{Case study}

The case is to predict the probabilistic lifecycle energy consumption of a single-family detached house, with one floor of $107.95 \mathrm{~m}^{2}$, one bathroom and three bedrooms, and full basement, using central air conditioning system, constructed in 1995. Currently, it is in excellent condition, located at Woodbine, Iowa. 1) The practical service lifetime of the building and the expected building condition at specific time are predicted by the developed building Markov deterioration model based on the historical condition record of similar buildings (from the local 480 residential samples data set); 2) The future temperature condition is estimated by Markov Chain model based on the local historical weather record; 3) The annual energy consumption variation is simulated as a joint process of the building deterioration and temperature change (i.e. the above two models); 4) To calculate annual energy consumption, the corresponding energy consumption probabilistic distribution for each joint state is estimated by neural network with the above available data set.

\subsection{Service lifetime estimation}

The observed building condition data for the buildings with different age are shown in Figure 8 and the statistical details are listed in Table 2. With these data, as is seen in Figure 9. The relationship between the condition rating and the building age is described by the following equation:

$$
\mathrm{RCR}=-0.0199 * \text { Age }+5.2308 .
$$

The building deterioration matrix is then derived based on Eqns (7) and (14) as the follows:

$\begin{array}{ccccccc}\text { Condition Rating } & 6 & 5 & 4 & 3 & 2 & 1 \\ 6 & 0.40 & 0.60 & 0.00 & 0.00 & 0.00 & 0.00 \\ 5 & 0.00 & 0.99 & 0.01 & 0.00 & 0.00 & 0.00 \\ 4 & 0.00 & 0.00 & 0.94 & 0.06 & 0.00 & 0.00 \\ 3 & 0.00 & 0.00 & 0.00 & 0.83 & 0.17 & 0.00 \\ 2 & 0.00 & 0.00 & 0.00 & 0.00 & 0.61 & 0.39 \\ 1 & 0.00 & 0.00 & 0.00 & 0.00 & 0.00 & 1.00\end{array}$

With Eqns (3) and (4), the expected condition at different time is calculated (Fig. 10). The case building is currently in the state of " 6 ". Accordingly, the service lifetime is estimated to be 89 years with the corresponding targeted condition of " 3 ", i.e. after 89 years, the residential will reach the condition below the rating "poor" and considered to be unfit for human habitation. This result is closer to the assumption of 100 years than 50 years and 75 years assumptions in the traditional approach, with the percentage error of $12 \%$. The consideration of building renovation is beyond the scope of this research due to the data availability issue and the extra difficulty in deriving the residential deterioration TPM.

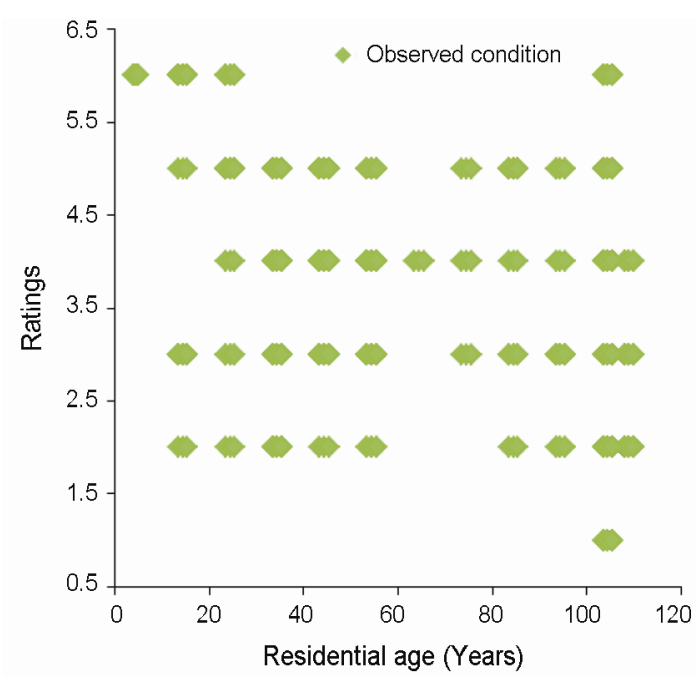

Fig. 8. Building condition rating versus building ages

Table 2. Frequency table with the variables of age and building

\begin{tabular}{|c|c|c|c|c|c|c|c|c|}
\hline \multirow{2}{*}{ 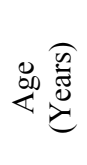 } & \multirow{2}{*}{ 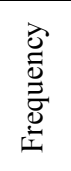 } & \multicolumn{6}{|c|}{$\begin{array}{l}\text { Residential Condition Rating } \\
\text { (RCR) }\end{array}$} & \multirow[b]{2}{*}{$\begin{array}{l}\text { Weighted } \\
\text { Mean }\end{array}$} \\
\hline & & 6 & 5 & 4 & 3 & 2 & 1 & \\
\hline 4 & 2 & 2 & 0 & 0 & 0 & 0 & $\overline{0}$ & 6.00 \\
\hline 14 & 16 & 11 & 1 & 0 & 3 & 1 & 0 & 5.12 \\
\hline 24 & 11 & 2 & 5 & 1 & 2 & 1 & 0 & 4.45 \\
\hline 34 & 41 & 0 & 14 & 4 & 17 & 6 & 0 & 3.63 \\
\hline 44 & 30 & 0 & 13 & 8 & 8 & 1 & 0 & 4.10 \\
\hline 54 & 19 & 0 & 5 & 7 & 6 & 1 & 0 & 3.84 \\
\hline 64 & 1 & 0 & 0 & 1 & 0 & 0 & 0 & 4.00 \\
\hline 74 & 3 & 0 & 1 & 1 & 1 & 0 & 0 & 4.00 \\
\hline 84 & 8 & 0 & 5 & 1 & 1 & 1 & 0 & 4.25 \\
\hline 94 & 9 & 0 & 1 & 1 & 5 & 2 & 0 & 3.11 \\
\hline 104 & 161 & 8 & 31 & 28 & 35 & 56 & 3 & 3.32 \\
\hline 108 & 8 & 0 & 0 & 3 & 2 & 3 & 0 & 3.00 \\
\hline Total & 309 & 23 & 76 & 55 & 80 & 72 & 3 & \\
\hline
\end{tabular}
condition

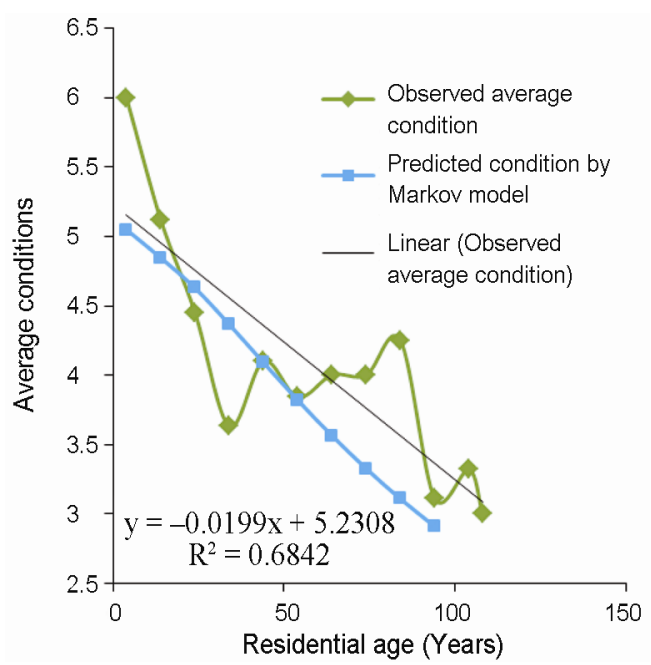

Fig. 9. Relationship between building's condition rating and age 


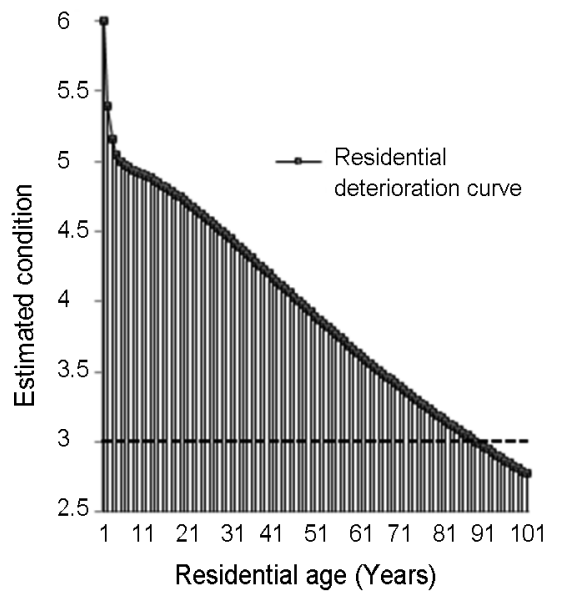

Fig. 10. Residential deterioration curve

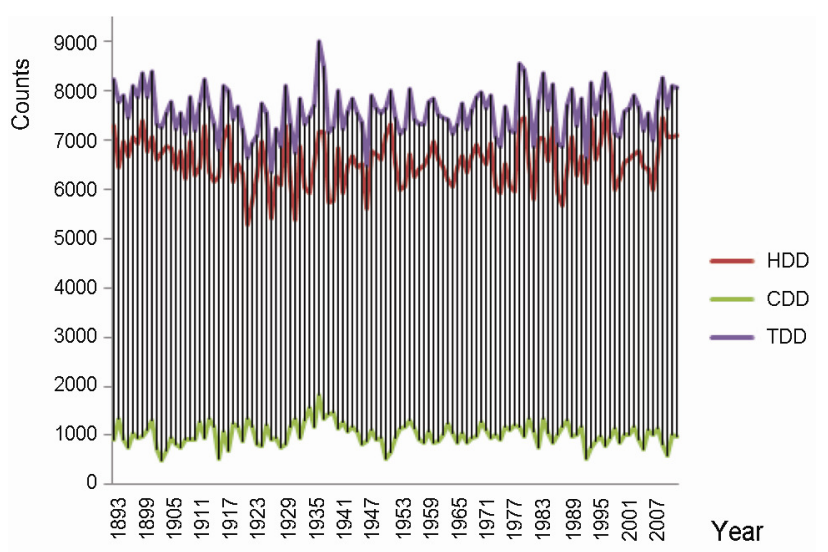

Fig. 11. Annual degree days profile in Woodbine, IA (HDD represents Heating Degree-Day; CDD represents Cooling Degree-Day; TDD represents Total Degree-Day)

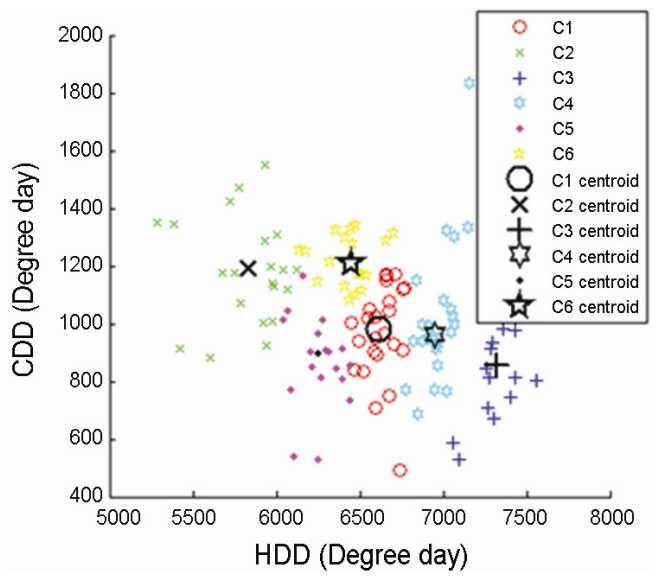

Fig. 12. Degree days clustering (6 classes)

\subsection{Degree-day level variation}

Longitudinal records for weather condition are relatively rich and thus counting method is useful for deriving degree-day level TPM. To make the referred period as complete as possible, the degree-day information of 119 years (1893-2011) is gathered from U.S. Cooperative Observer Program (COOP) Logan site which is around eight miles away from Woodbine, Iowa (UNL 2012). For the missing data, the most pertinent average value is used.
The degree-day profile is shown in Figure 11. It can be seen there is large variation in heating degree-day ( $43 \%$ error between the maximum and the minimum), cooling degree-day $(274 \%$ error between the maximum and the minimum) and total degree-day ( $42 \%$ error between the maximum and the minimum). After degree-day information is grouped into six classes by Fuzzy C-Means clustering (Fig. 12), the degree-day level TPM is calculated with the counting method (Eqn (5)):

$\begin{array}{ccccccc}\text { DD Level } & C 1 & C 2 & C 3 & C 4 & C 5 & C 6 \\ C 1 & 0.33 & 0.08 & 0.13 & 0.25 & 0.13 & 0.08 \\ C 2 & 0.10 & 0.33 & 0.05 & 0.14 & 0.14 & 0.24 \\ C 3 & 0.21 & 0.14 & 0.21 & 0.14 & 0.00 & 0.29 \\ C 4 & 0.17 & 0.17 & 0.13 & 0.22 & 0.22 & 0.09 \\ C 5 & 0.28 & 0.11 & 0.11 & 0.22 & 0.17 & 0.11 \\ C 6 & 0.11 & 0.22 & 0.06 & 0.22 & 0.22 & 0.17\end{array}$

\subsection{Annual energy consumption TPM}

As stated above, annual energy consumption transition process is the jointed process of building deterioration and degree-day level transition. The 36 possible joint states are created (e.g. $(6, C 1),(6, C 2),(6, C 3) \ldots)$. The transition probability between the joint states is derived based on the obtained building deteriorate rate and degree-day level transition probability via Eqn (10).

\subsection{Energy distribution for the different joint states}

For each building sample, the parameters including the construction year (e.g. 1900), the building style (e.g. 1.5 story), the square footage, the basement type (e.g. partial), the number of bedrooms and bathrooms, the building condition rating (e.g. excellent), the monthly electricity, gas consumption (from the year 2008 to the year 2010), and the corresponding monthly cooling degreedays, heating degree-days are collected. For convenient aggregation and comparison, the delivered energy is converted into the form of primary energy (with the conversion coefficients for electricity and gas being 3.412 and 1.027 , respectively). The parameter EUI in terms of the annual primary energy is used as targeted output and the other parameters are adopted as inputs for neural network learning and predicting. From Figure 13, it can be seen there is large variation in EUI for the sampled buildings.

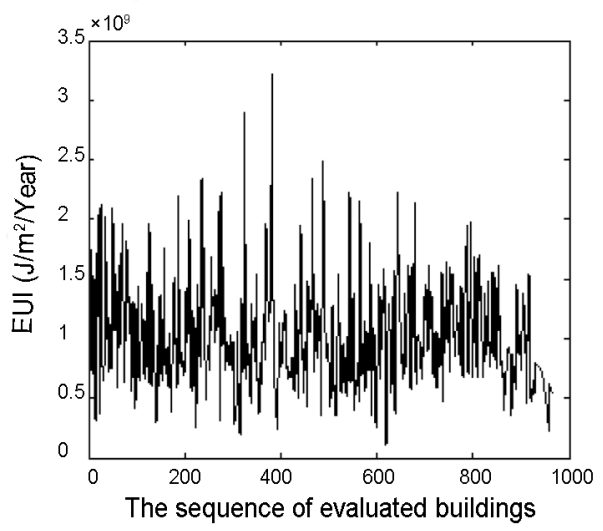

Fig. 13. Variation in Energy Use Intensity for the evaluated building samples (3 years data) 
The simple traditional deterministic lifecycle energy consumption model will definitely produce the results with large errors. For each possible joint state, the probabilistic distribution of EUI is generated by changing the above input parameters, with the building style of one story.

\subsection{Lifecycle energy consumption results of the proposed stochastic approach}

Based on the estimated service life, using the annual energy consumption Markov transition model, the joint condition vector is obtained with the initial condition of $(6, C 4)$. Combining the probabilistic EUI distribution, the probabilistic EUI for each year is calculated and accumulated to the probabilistic lifecycle energy consumption (Figs 14 and 15). Normal distribution is fitted with mean value of $1.93 \times 10^{11} \mathrm{~J}$ and the standard variation of $9.16 \times 10^{9} \mathrm{~J}$. The COV value for the resulting lifecycle energy consumption is 0.05 . The $(10 \%, 90 \%)$ certainty interval is $\left(1.81 \times 10^{11}, 2.05 \times 10^{11}\right) \mathrm{J}$, which means the resulting values lying in this interval takes up $80 \%$ of the all possible values.

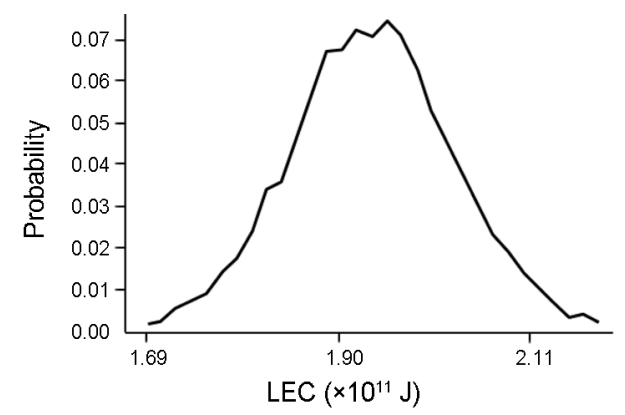

Fig. 14. Lifecycle energy consumption (Probability density function)

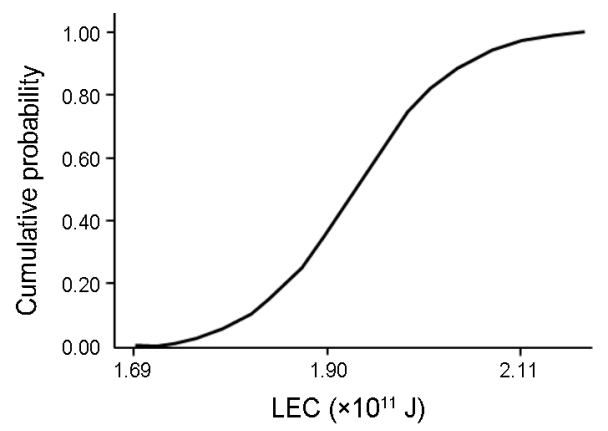

Fig. 15. Lifecycle energy consumption (Cumulative distribution function)

\subsection{Comparing with the traditional approach}

With the traditional approach, the uncertainty associated with the three scenarios (50 years, 75 years, and 100 years) results which are obtained according to the rule of taking deterministic EUI from similar buildings, is quantified (Figs 16 and 17). It is assumed that the chance of each EUI value in the data set for one story building is equal. From Figure 16, it can be seen that the resulting distributions are quite different from the one of the proposed stochastic model, with the $\mathrm{COV}$ of 0.37 , which means there is large uncertainty in the traditional approach result even with the fixed assumption of service lifetime. Therefore, the result of the deterministic result is very problematic. The proposed stochastic approach can produce the relative percentage decrements (RPD) of $86.5 \%$, which is calculated using Eqn (15). It indicates that the proposed approach can significantly reduce the uncertainty in the lifecycle energy consumption result by simulating the longitudinal uncertainty in building condition and degree-day level through Markov Chain.

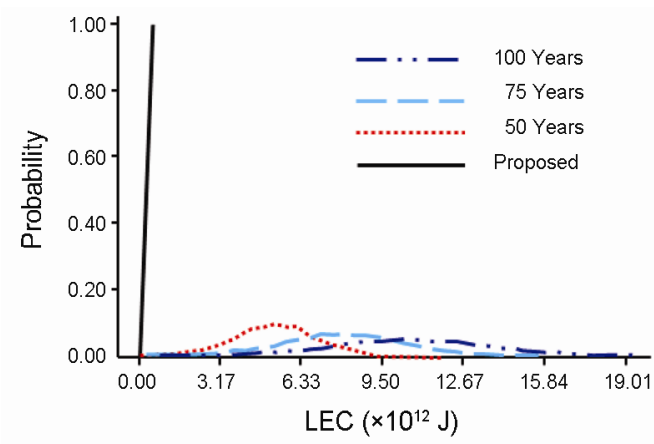

Fig. 16. Comparison of the results from different methods (Probability density function)

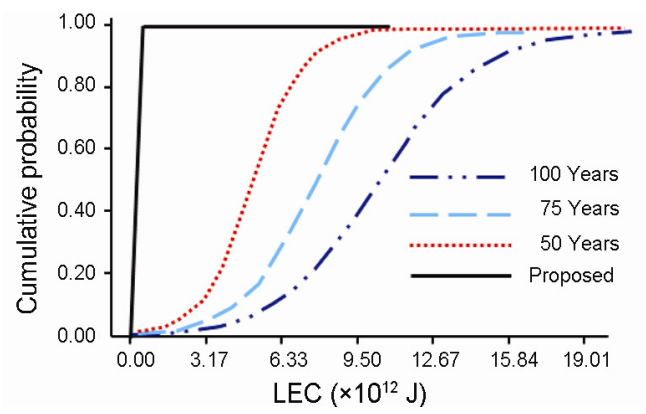

Fig. 17. Comparison of the results from different methods (Cumulative distribution function)

$\mathrm{RPD}=[(\mathrm{COV}$ of the traditional approach result $-\mathrm{COV}$ of the proposed stochastic approach result) / COV of the traditional approach result $] \times 100 \%$.

The 10-90\% certainty interval distances between distributions are shown in Table 3, from which it can be seen that the result of the traditional approach with 50 -year service life assumption is closer to that of the proposed stochastic approach (i.e. indicated by closer distance) although the predicted service lifetime is closer to the 100 years assumption.

Table 3. The $10-90 \%$ lifecycle energy consumption certainty interval distances

\begin{tabular}{cccc}
\hline Distance $\left(D\left(I_{p}, I_{q}\right)\right)$ & $T_{50}$ & $T_{75}$ & $T_{100}$ \\
\hline Distance to $\mathrm{S}\left(\times 10^{12} \mathrm{~J}\right)$ & 7.88 & 11.92 & 16.04 \\
\hline
\end{tabular}

Notes: "S" denotes the proposed stochastic approach; " $T_{50}$ " denotes the traditional approach with service lifetime of 50 years; " $T_{75}$ " denotes the traditional approach with service lifetime of 75 years; " $T_{100}$ " denotes the traditional approach with service lifetime of 100 years. 
Theoretically, the proposed stochastic approach needs to be validated by checking the closeness between its resulting distribution and the practical measured lifecycle energy consumption data of the case building in terms of predefined criteria, such as $\mathrm{COV}$ and distance. This requires large amount of data within a long period (may be around 100 years), which is not practical and even impossible due to the data scarcity and long period constraint (de Wilde et al. 2011). A practical approach is to compare the available measured data for several years of annual energy consumption with the corresponding results of the traditional approach and the proposed stochastic approach. The random three years EUI data are used to perform validation. The annual EUI results for the years of 2008, 2009 and 2010 are mutually compared (Fig. 18). The average $\mathrm{COV}$ and distance results are shown in Table 4.

Table 4. Results (averaged) comparison for the annual Energy Use Intensity distributions

\begin{tabular}{cccc}
\hline Measures & $\mathrm{S}$ & $\mathrm{T}$ & $\mathrm{M}$ \\
\hline$C O V$ & 0.08 & 0.36 & 0.16 \\
Distance to $\mathrm{S}\left(\times 10^{8} \mathrm{~J} / \mathrm{m}^{2}\right)$ & 0 & 4.81 & 1.18 \\
Distance to $\mathrm{M}\left(\times 10^{8} \mathrm{~J} / \mathrm{m}^{2}\right)$ & 1.18 & 3.79 & 0 \\
\hline
\end{tabular}

Notes: "S" denotes the proposed stochastic approach; "T" denotes the traditional approach; "M" denotes the measured data.

As stated before, the validation remains a challenging task for most of the LCA (Life Cycle Assessment) related research. In this case, it is difficult to find the desired validation residential samples (with same floor area, same age, same structure and so on). Therefore, the measured data is only an approximate value. From Table 4 , the distribution resulting from the proposed stochastic approach shows the smallest $\mathrm{COV}$ value which implies that the application of Markov Chain to model the longitudinal uncertainty in building condition and temperature change has reduced much uncertainty. It also appears that the proposed stochastic approach result is closer to the measured data in terms of distance value.

\section{Conclusion}

Accurate prediction of lifecycle energy consumption is critical for improving residential building LCA. Due to the complex nature of building energy system, it is quite difficult to achieve such an accurate prediction regardless of the used approach (Zhao, Magoulès 2012). Traditionally, lifecycle energy consumption is often projected with deterministic linear-average approach which ignores the longitudinal variability of ambient temperature and the residential thermal condition. The presented study attempts to depict the updating building properties by a comprehensive term "Building Condition" with which the service lifetime is estimated and the overall thermal condition is indicated. The degree-day information is used to represent the temperature conditions. After the residential deterioration process and the temperature variation are separately modelled by Markov Chain, the annual energy consumption variation is modelled by jointing the above two Markov Chains with the joint state of building condition and degree-day level. The energy consumption for each joint state is estimated by neural network using the historical data record and fitted with probabilistic distribution, considering other factors, like basement type, number of bedrooms and so forth. Based on the joint Markov Chain and the energy distribution for each joint state, the lifecycle energy consumption is aggregated by probabilistic approach.

The case study shows the service lifetime assumption in the traditional approach is relatively arbitrary. This case residential shows the assumption of 100 years is more reasonable in the case area but it is not always the truth because many factors can affect the residential longevity. The traditional approach shows large uncertainty and unreliability which means the decision made based on the traditional approach is quite risky. The proposed stochastic approach can produce much narrower distribution and seems closer to the measured data, which indicates the longitudinal uncertainty in both building thermal condition and temperature can explain much uncertainty in residential energy performance variation. The final lifecycle energy consumption result distribution is closer to that of the traditional approach with 50 years assumption (not the 100 years consumption) because the deterministic EUIs adopted in the traditional approach are from the context of the extreme climate (with greater heating degree-day and cooling degree-day).

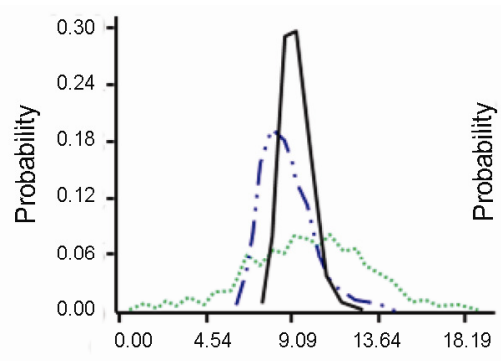

2008 profile

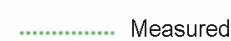

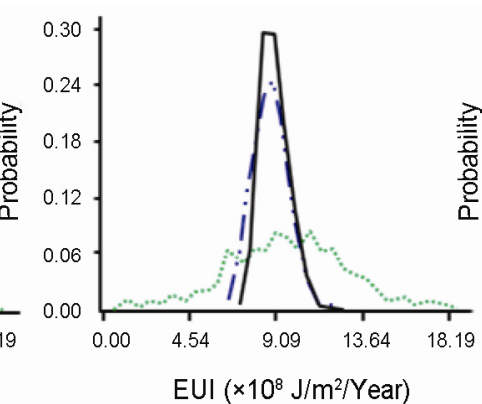

2009 profile

Predicted

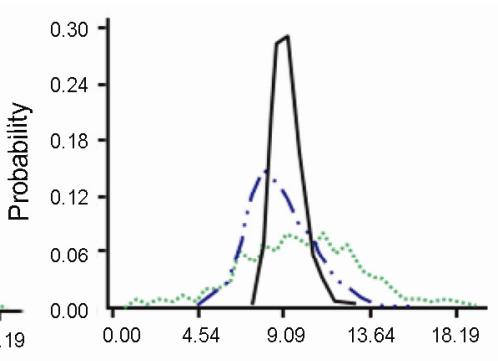

2010 profile

Fig. 18. Comparison of results of different approaches 
The case study confirms the conclusion from de Wilde et al. (2011) that the stochastic approach is feasible but needs much reliable data and mathematical computations. As the number of Markov states increases, the computation burden becomes heavier. It also presents an example of the impact of product service lifetime on its LCA result. However, the prediction of the individual building service lifetime is still a challenging task and needs many assumptions (Aktas, Bilec 2012). Although Markov process based deterioration model appears better than other methods, there are still subjectivities in the process (Carnahan et al. 1987; Ortiz-Garcia et al. 2006; Madanat et al. 1995; Mc Duling 2006; de Wilde et al. 2011).

\section{Limitations of the proposed model}

Although the proposed approach improved the lifecycle operation energy prediction results, it only addresses variability of longitudinal building deterioration and degree days, which are primarily associated with the energy consumption of cooling and heating. Energy consumption variations due to different occupants' behaviours associated with home appliances electronic and electrical devices and equipment are not addressed in the proposed model. Totally different models are needed to deal with human factors in order to model such variations. It is our understanding that significant part of the differences between the measured results and the predicted results in Figure 18 can be explained by the omitted occupants' behaviour factors. Future study can be extended to combining both physical factors and occupants' behaviour factors in lifecycle energy consumption predictions.

\section{Acknowledgement}

The authors would like to thank US Environmental Protection Agency for the support through Grant CR83419301-1.

\section{Disclaimer}

The U.S. Environmental Protection Agency, through its Office of Research and Development, funded and managed, or partially funded and collaborated in, the research described herein. Any opinions expressed in this paper are those of the author (s) and do not necessarily reflect the views of the Agency, therefore, no official endorsement should be inferred. Any mention of trade names or commercial products does not constitute endorsement or recommendation for use.

\section{References}

Agrawal, A. K.; Kawaguchi, A.; Chen, Z. 2009. Bridge element deterioration rates. Project Report No. C-01-51, New York State Department of Transportation.

Aktas, C. B.; Bilec, M. M. 2012. Impact of lifetime on US residential building LCA results, The International Journal of Life Cycle Assessment 17(3): 337-349. http://dx.doi.org/10.1007/s11367-011-0363-x

Barry, N. A. 2011. Determining a community retrofit strategy for the aging housing stock using utility and assessor data. Doctoral Dissertation, University of Nebraska-Lincoln, Lincoln, NE.
Biekša, D.; Šiupšinskas, G.; Martinaitis, V.; Jaraminienè, E. 2011. Energy efficiency challenges in multi-apartment building renovation in Lithuania, Journal of Civil Engineering and Management 17(4): 467-475. http://dx.doi.org/10.3846/13923730.2011.622408

Camahan, J. V.; Davis, W. J.; Shahin, M. Y.; Keane, P. L.; Wu, M. I. 1987. Optimal maintenance decisions for pavement management, Journal of Transportation Engineering 113(5): 554-572. http://dx.doi.org/10.1061/ (ASCE)0733-947X(1987)113:5(554)

Catalina, T.; Virgone, J.; Blanco, E. 2008. Development and validation of regression models to predict monthly heating demand for residential buildings, Energy and Buildings 40(10): 1825-1832. http://dx.doi.org/10.1016/j.enbuild.2008.04.001

Coffelt, D. P.; Hendrickson, C. T.; Healey, S. T. 2010. Inspection, condition assessment, and management decisions for commercial roof systems, Journal of Architectural Engineering 16(3): 94-99.

http://dx.doi.org/10.1061/(ASCE)AE.1943-5568.0000014

Cole, R. J.; Kernan, P. C. 1996. Life-cycle energy use in office buildings, Building and Environment 31(4): 307-317. http://dx.doi.org/10.1016/0360-1323(96)00017-0

Day, A. R.; Karayiannis, T. G. 1999. A new degree-day model for estimating energy demand in buildings, Building Services Engineering Research and Technology 20(4): 173178. http://dx.doi.org/10.1177/014362449902000402

de Wilde, P.; Tian, W. 2011. Towards probabilistic performance metrics for climate change impact studies, Energy and Buildings 43(11): 3013-3018. http://dx.doi.org/10.1016/j.enbuild.2011.07.014

de Wilde, P.; Tian, W.; Augenbroe, G. 2011. Longitudinal prediction of the operational energy use of buildings, Building and Environment 46(8): 1670-1680. http://dx.doi.org/10.1016/j.buildenv.2011.02.006

Dhar, A.; Reddy, T. A.; Claridge, D. E. 1998. Modeling hourly energy use in commercial buildings with Fourrier series functional form, Journal of Solar Energy Engineering 120(3): 217-223. http://dx.doi.org/10.1115/1.2888072

Dunn, J. C. A. 1973. Fuzzy relative of the ISODATA process and its use in detecting compact well-separated clusters, Journal of Cybernetics 3: 32-57. http://dx.doi.org/10.1080/01969727308546046

Fay, R.; Treloar, G.; Iyer-Raniga, U. 2000. Life-cycle energy analysis of buildings: a case study, Building Research \& Information 28(1): 31-41.

http://dx.doi.org/10.1080/096132100369073

Guerra-Santin, O.; Itard, L. 2010. Occupants' behavior: determinants and effects on residential heating consumption, Building Research \& Information 38(3): 318-338. http://dx.doi.org/10.1080/09613211003661074

Hussain, M. A.; Ansari, M. R. K. 2010. Some insights of local and global temperature dynamics, The Arabian Journal for Science and Engineering 35(1A): 103-113.

Igel, C.; Hüsken, M. 2000. Improving the RPROP learning algorithm, in Proceedings of the Second International Symposium on Neural Computation, NC'2000, ICSC Academic Press, 115-121.

Jiang, Y.; Saito, M.; Sinha, K. C. 1988. Bridge performance prediction model using the Markov chain, Transportation Research Record 1180: 25-32.

Jordan, P.; Talkner, P. 2000. A seasonal Markov chain model for the weather in the central Alps, Tellus A 52(4): 455469. http://dx.doi.org/10.1034/j.1600-0870.2000.00106.x 
Junnila, S.; Horvath, A. 2003. Life-cycle environmental effects of an office building, Journal of Infrastructure Systems 9(4): 157-66. http://dx.doi.org/10.1061/(ASCE)10760342(2003)9:4(157)

Kamaitis, Z. 2009. Modelling of corrosion protection as standby system for coated reinforced concrete structures, Journal of Civil Engineering and Management 15(4): 387-394. http://dx.doi.org/10.3846/1392-3730.2009.15.387-394

Kaynakli, O. 2011. Parametric investigation of optimum thermal insulation thickness for external walls, Energies 4(6): 913-927. http://dx.doi.org/10.3390/en4060913

Khasreen, M. M.; Banfill, P. F. G.; Menzies, G. F. 2009. Life cycle assessment and the environmental impact of buildings: a review, Sustainability 1: 674-701. http://dx.doi.org/10.3390/su1030674

Kim, J. J.; Moon, J. W. 2009. Impact of insulation on building energy consumption, in Eleventh International IBPSA Conference, July 27-30, 2009, Glasgow, Scotland.

Madanat, S.; Mishalani, R.; Ibrahim, W. H. W. 1995. Estimation of infrastructure transition probabilities from condition rating data, Journal of Infrastructure Systems 1(2): 120-125. http://dx.doi.org/10.1061/(ASCE)1076-0342 (1995)1:2(120)

Mc Duling, J. J. 2006. Towards the development of transition probability matrices in the Markovian model for the predicted service life of buildings. Doctoral Thesis, University of Pretoria.

Nicolis, C. 1990. Chaotic dynamics, Markov processes and climate predictability, Tellus 42A: 401-412.

Ortiz-Garcia, J. J.; Costello, S. B.; Snaith, M. S. 2006. Derivation of transition probability matrices for pavement deterioration modeling, Journal of Transportation Engineering 132(2): 141-161. http://dx.doi.org/10.1061/(ASCE) 0733-947X(2006)132:2(141)

Riveros, G. A.; Arredondo, E. 2010. Predicting deterioration of navigation steel hydraulic structures with Markov chain and Latin hypercube simulation. Coastal and Hydraulics Engineering Technical Note ERDC/CHL CHETN-IX-25.

Ross, S. M. 1996. Stochastic Processes. $2^{\text {nd }}$ ed. John Wiley \& Sons, Inc. $510 \mathrm{p}$.

Stamp, M. 2012. A revealing introduction to hidden Markov models [online] [cited 06 January 2012]. Available from Internet: http://www.cs.sjsu.edu/faculty/stamp/RUA/HMM.pdf

Straub, A. 2009. Dutch standard for condition assessment of buildings, Structural Survey 27(1): 23-35. http://dx.doi.org/10.1108/02630800910941665

Trombe, P-J.; Pinson, P.; Madsen, H. 2012. A general probabilistic forecasting framework for offshore wind power fluctuations, Energies 5(3): 621-657. http://dx.doi.org/10.3390/en5030621

Tsikaloudaki, K.; Laskos, K.; Bikas, D. 2012. On the establishment of climatic zones in Europe with regard to the energy performance of buildings, Energies 5(1): 32-44.
Tso, G. K. F.; Yau, K. K. W. 2007. Predicting electricity energy consumption: a comparison of regression analysis, decision tree and neural networks, Energy 32(9): 1761-1768. http://dx.doi.org/10.1016/j.energy.2006.11.010

UNL. LOGAN, IA: Monthly total heating degree days, [online] [cited 05 October 2012]. Available from Internet: http://www.hprcc.unl.edu/cgi-bin/cli perl lib/cliMAIN. pl?ia4894

Wang, C.; Yan, D.; Jiang, Y. 2011b. A novel approach for building occupancy simulation, Building Simulation 4(2): 149-167. http://dx.doi.org/10.1007/s12273-011-0044-5

Wang, E.; Shen, Z.; Berryman, C. 2011a. A building LCA case study using Autodesk Ecotect and BIM model, in $47^{\text {th }}$ ASC Annual International Conference Proceedings, April 6-9, Omaha, Nebraska, USA.

Wang, E.; Shen, Z.; Neal, J.; Shi, J.; Berryman, C.; Schwer, A. 2012. An AHP-weighted aggregated data quality indicator (AWADQI) approach for estimating embodied energy of building materials, The International Journal of Life $C y$ cle Assessment 17(6): 764-773. http://dx.doi.org/10.1007/s11367-012-0417-8

Xu, Z.; Sun, Z. 2002. Priority method for a kind of multiattribute decision-making problems, Journal of Manage Science in China 5(3): 35-39.

Yalcintas, M.; Akkurt, S. 2005. Artificial neural networks applications in building energy predictions and a case study for tropical climates, International Journal of Energy Research 29(10): 891-901. http://dx.doi.org/10.1002/er.1105

Yang, H.; Li, Y.; Lu, L.; Qi, R. 2011. First order multivariate Markov chain model for generating annual weather data for Hong Kong, Energy and Buildings 43(9): 2371-2377. http://dx.doi.org/10.1016/j.enbuild.2011.05.035

Yang, J.; Rivard, H.; Zmeureanu, R. 2005. On-line building energy prediction using adaptive artificial neural networks, Energy and Buildings 37(12): 1250-1259. http://dx.doi.org/10.1016/j.enbuild.2005.02.005

Yu, W.; Li, B.; Lei, Y.; Liu, M. 2011. Analysis of a residential building energy consumption demand model, Energies 4(3): 475-487. http://dx.doi.org/10.3390/en4030475

Zhang, Y.; Augenbroe, G.; Vidakovic, B. 2005. Uncertainty analysis in using Markov chain model to predict roof life cycle performance, in 10 DBMC International Conference on Durability of Building Materials and Components, 2005, Lyon, France.

Zhao, H.; Magoulès, F. 2011. Feature selection for support vector regression in the application of building energy prediction, in $9^{\text {th }}$ IEEE International Symposium on Applied Machine Intelligence and Informatics, 27-29 January, 2011, Smolenice, Slovakia.

Zhao, H.; Magoulès, F. 2012. A review on the prediction of building energy consumption, Renewable and Sustainable Energy Reviews 16(6): 3586-3592. http://dx.doi.org/10.1016/j.rser.2012.02.049

Endong WANG. PhD student of Durham School of Architectural Engineering and Construction in the College of Engineering at the University of Nebraska-Lincoln. His research focuses on uncertainties in building life cycle assessment.

Zhigang SHEN. Assistant Professor of Durham School of Architectural Engineering and Construction in the College of Engineering at the University of Nebraska-Lincoln. In his research areas he was awarded multiple federal research grants from NSF, EPA, DOE and DOL of the United States. His main research interests are energy efficient building design and construction, virtual built environment, and virtual learning and training in design and construction. 